\title{
Analysis of energy supply disturbances in Lithuania
}

\author{
J. Augutis ${ }^{1,2}$, V. Matuziene ${ }^{1}$, R. Krikstolaitis ${ }^{1,2}$ \& E. Ušpuras ${ }^{1}$ \\ ${ }^{1}$ Lithuanian Energy Institute, Lithuania \\ ${ }^{2}$ Vytautas Magnus University, Lithuania
}

\begin{abstract}
The Lithuanian situation of safety and security of the energy supply is quite complicated. Few countries supply primary energy sources and there are no networks of gas, oil and electricity to Western Europe; the transmission network needs modernization.

In this paper a methodological scheme of energy safety and security of supply is presented, which is well reasoned by scientific methods and would solve these problems. The methodology includes the following stages: analysis of scenarios of disturbances, economical modelling, reliability modelling of supply systems, and analysis of consequences.

Analysis of energy supply disturbances and evaluating their appearance probabilities are performed. Long term scenarios evaluate new technologies (e.g., new power plants) and their influence on energy supply security. A mathematical model of energy disturbances is created in this paper; it is chosen and modelled based on 110 different scenarios of energy disturbances. Critical situations are assessed by costs, which have to be paid for to secure a proper supply of energy.
\end{abstract}

Keywords: energy security of supply, disturbances of energy supply.

\section{Introduction}

Energy supply is essential to the functioning of modern economies. However, the uneven distribution of energy supply among countries and the critical need for energy has led to significant vulnerabilities.

The International Energy Agency describes the concept of "energy supply security" as a reliable possibility to obtain proper energy, in quantity, for a 
reasonable price. The description of energy security, according to the World Energy Council, is the following: it is the protection of citizens, society, economics and state against threats arising to the reliable fuel and energy supply.

Reliable, sustainable and effective energy consumption is the main requirement for the National Energy Consumption Efficiency Improvement Program for 2011-2015 [1] and the Lithuanian energy strategy [2].

At present there are no unitary full-scale (including economical, technological, political and other aspects) criteria or methods, indicating how to estimate the quantitative, permissible, strategic dependence of energy supply from another country which, due to different reasons, may be considered an unreliable supplier or which may use energy and other raw materials supplied for political purposes. Assessments of energy supply security are usually based on political motives or on the criteria of individual researchers; more often it is just an overview of probable supply alternatives.

The aim of this work is to create a methodology for estimating the security of the energy supply in Lithuania. The paper includes a short presentation of Lithuanian energy security problems, a small review of the principal scheme of methodology proposed for analysis of the energy supply security and modelling of supply disturbances. It will be well-reasoned by scientific methodology and is being developed for Lithuania for the first time.

One of the most complicated trends in this scientific theme is a rapid decrease of possible energy supply disturbances, such as technical accidents of energy systems, natural disasters and catastrophes, terrorism acts, and energy sources, disturbances of energy supply raw materials, economic blockades, economical and political crises, their probability and frequency analysis and development of probabilistic models. In analysing scenarios of energy supply disturbances, accidents or crises, it is expedient to have modelling measures which would enable the evaluation of a process of energy production, supply and distribution among different types of energy, the possible impact of energy decrease or disruption on the other industry branches, the rise of energy prices, quantities and dynamics of energy supplied to consumers, losses experienced for individual industry branches and the Lithuanian economy. With the help of these models it is possible to evaluate and compare different development strategies of energy supply, possible variants of energy sources and the impact of different energy types on Lithuanian energy supply security.

\section{Present situation of Lithuanian energy supply security}

The Lithuanian situation of safety and security of the energy supply is quite complicated in comparison to other European countries: few countries supply primary energy sources, there are no networks of gas, oil and electricity to Western Europe, and the transmission grid needs modernization.

Nuclear is still the main source of electric energy in Lithuania: it covers $60-86 \%$ of total electricity production. Nuclear energy in Lithuania is imported only from Russia, taking into account the fact that reactors operating in the Ignalina Nuclear Power Plant (NPP) are RBMK (reactors of high power of the 
channel) type, for which fuel is produced only in Russia. Nuclear fuel has great resistance to short interferences of energy supply. On the other hand, nuclear energy is very sensitive to breakdowns. In the case of a big breakdown it could stop all NPP for a short or long time, no matter in what country or which NPP. The capacity of power stations reaches almost $5000 \mathrm{MW}$. 26\% of capacity is generated by NPP, $53 \%$ by thermal power plants, and $21 \%$ by hydropower plants (including the capacity of the Kruonis Pumped Storage Plan) in Lithuania [3]. So the closing of the Ignalina NPP reactor in 2009 is the main challenge for the development of an energy system and energy supply security in Lithuania.

The Lithuanian transfer network is integrated only to neighbouring energy systems: four $330 \mathrm{kV}$ and three $110 \mathrm{kV}$ power transmission lines connect to the Latvia energy system; five $330 \mathrm{kV}$ and seven $110 \mathrm{kV}$ power transmission lines connect to the Belarus energy system; three $330 \mathrm{kV}$ and three $110 \mathrm{kV}$ power transmission lines connect to the Kaliningrad district of the Russian Federation. There is no connection to West European countries. Therefore, in the national program, one of the main points is to build strategic connections to Poland and Sweden [1].

At the moment, natural gas, including natural gas used as a raw material for fertilizer production, comprises $28.4 \%$ of the primary energy balance. $3.8 \mathrm{bln} . \mathrm{m}^{3}$ of it was imported in 2005 [2]. 100\% of natural gas is imported from Russia. The capability of incoming gas pipes reaches 6 billion $\mathrm{m}^{3}$ per year - says the national program of energy consumption [1]. Lithuania transfers approximately $0.72 \mathrm{bln}$. $\mathrm{m}^{3}$ gas by transit to the Kaliningrad district of the Russian Federation. The Lithuanian gas supply network is connected to the Latvian gas pipes network, but it isn't connected to the Western European gas network. If it becomes a necessity it would be possible to transfer up to $500 \mathrm{mln} . \mathrm{m}^{3}$ gas per year through Latvia, however capacities of natural gas supply to Latvia are very limited.

In the Lithuanian oil sector there is "Mazeikiu nafta" with two terminals: Butinge and "Klaipedos nafta". The only Baltic refinery company of joint stock "Mazeikiu nafta" reprocessed $8.9 \mathrm{mln}$. tons of oil in 2005. Raw oil can be imported to Lithuanian from different countries, but it is imported from Russia, Kazachstan via the Butinge terminal. Historically, the primary feedstock has been Russian crude oil transported via the Druzhba pipeline; however the relevant branch of this system has been closed in Russian territory since July 2006, apparently for repairs or political reasons. Crude oil is now being supplied by the Butinge Terminal.

The district heating sector in Lithuania is centralized and needs modernisation. There are no inter-urban or international pipelines. Because of these reasons it is important to warrant security of supply. The biggest part of fuel output for heat generation is from natural gas $-80.6 \%$. This tendency to use natural gas is almost unchanged since 2000. Potentials of the heat sector could be associated with using wider biomass. The wood part of the fuel balance has increased to $10 \%$. Using geothermal energy has increased for individual house heating. So it is possible to state that Lithuania's energy dependency upon imported fuel decreased in the heat sector. 
Lithuania is one of the few European countries that has almost none of its own conventional energy resources (coal, oil, natural gas, uranium and large hydro energy resources). The majority of the primary energy resources were imported in Lithuania in 2000-2006 (Figure 1). The absolute majority of imported primary energy resources are obtained from Russia (natural gas $100 \%$, coal and peat $-90.8 \%$, oil $-91.8 \%$, nuclear fuel $-100 \%$ ).

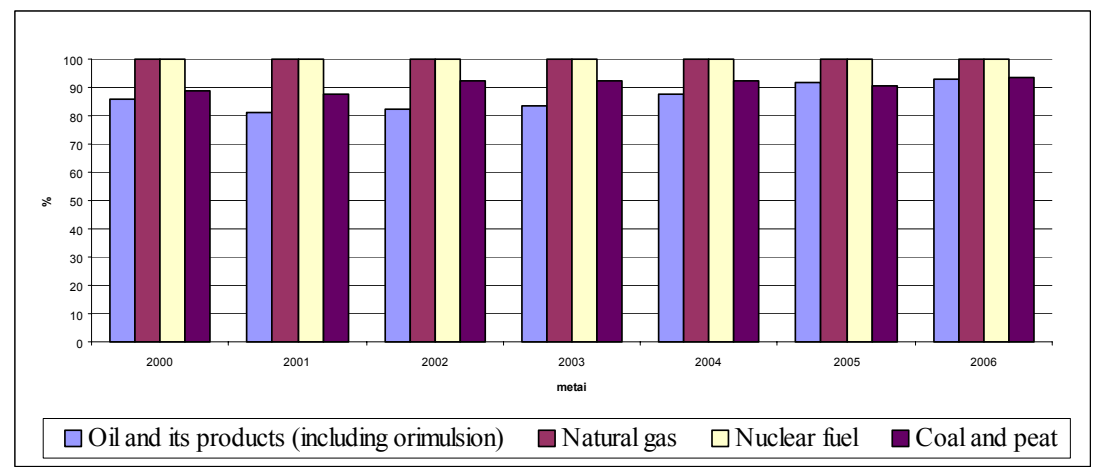

Figure 1: $\quad$ The part of imported primary energy resources used in Lithuania 2000-2006.

So the main threats to energy supply security in Lithuania are:

- high level of supply of primary energy resources from one country (natural gas, nuclear fuel);

- closing of Ignalina NPP and decommissioning of it's reactors until the installation of competitive power generating sources and implementation of tools of the energy supply network, especially intersystem connection to Poland and Sweden;

- old heat supply systems and electricity transmission network, slow modernization of technologies.

Those threats and others are shown in the latest Lithuanian energy strategy.

\section{The methodology of energy supply security}

The above mentioned threats force us to choose a comprehensive methodology of energy supply security research, which includes all parts of security analysis: scenarios of disturbances, economical modelling, reliability of technical systems modelling, consequences analysis. The scheme of the methodology is presented in Figure 2.

For analysis of scenarios of disturbances we need input such as statistical data of breaking of the energy supply security and the evaluation of experts. The most probable evaluation of experts should be selected using Fuzzy logics, Bayesian approach, Decision analysis or possibilities theory. Results of the analysis are disturbance scenarios and evaluation of their appearance probabilities. Also, 
short term scenarios, which evaluate real state and short breaks of supply because of transmission system failures and political disturbances and long term scenarios, which evaluate the influence of new technologies (e.g. new power plants) on energy supply security should be researched separately.

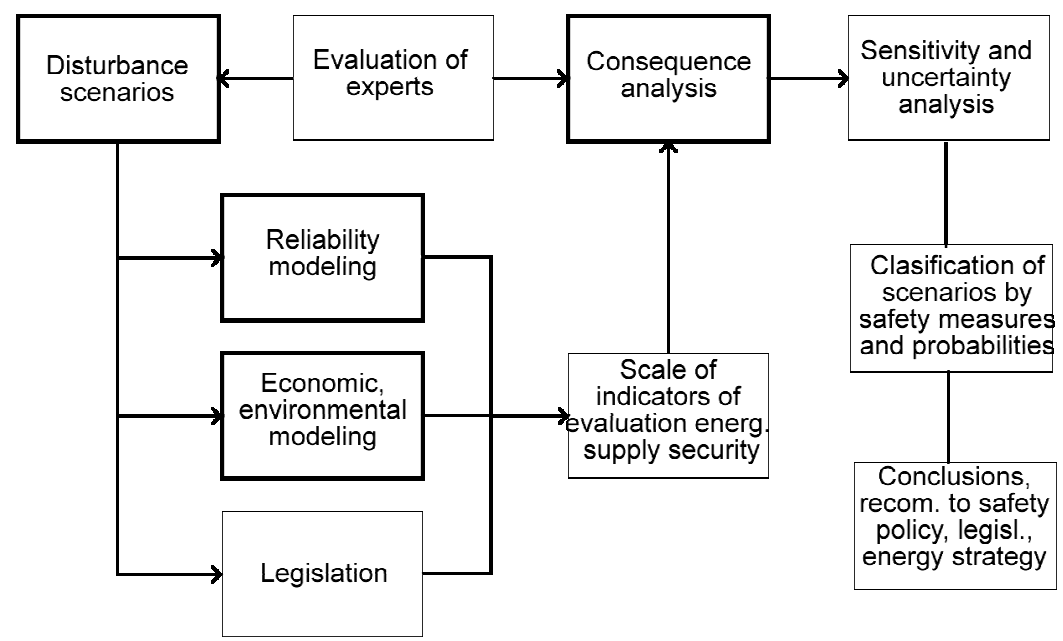

Figure 2: $\quad$ The scheme of full-scale suggested methodology.

Energy disturbances were modelled using the Lithuanian energy system mathematical model developed in MESSAGE analytical software [4]. The tool is designed for planning the energy sector in the long term perspective, where the technological process could be predictable. Its optimization function is the minimization of work of the energy system during the considered period. Using the model it is possible to assess and compare different energy development strategies, alternatives of consumption, different energy resources or new energy technologies. In applying sensitivity analysis it is possible to investigate the influence of particular indicators to the functioning of the energy system. The main result of modelling that is useful for security of the energy supply is the costs of the entire energy system, the limitations of the primary energy resources, and of existing environmental policies.

Reliability analysis evaluates the influence of networks and systems of energy transmission to energy safety. Simulating the Lithuanian power transmission network model shows the operation of the network, then the natural or simulated breakdown occurring and then analyses the natural or simulated failure scenarios when separate elements (transfer lines, substations, and generators) are eliminated from the network. Expected results for the security of energy supply evaluation scale are the quantity of unsupplied energy, energy break time, "cascade" effects of energy system failures, unreliable links of the system, and time taken for system renovation after breakdowns. 
Probabilities of consequences are evaluated using statistical data and experts approach. In decision analysis, sequences of decisions and uncertain events are examined. A decision tree is often used as a visual display and a device for computing the probability distributions corresponding to different decision alternatives, and then evaluating these to find the best decision. Results of the consequent analysis are scenarios of possible consequences and probabilities of failures. Consequences can also be classified as critical and safe. The greatest likelihood of consequences can be found using sensitivity analysis.

\section{Economical modelling of energy supply disturbance scenarios}

\subsection{Energy disturbances}

One of the primary and most important parts of assessment of energy supply security is the development of scenarios of energy source supply. Development of disturbance scenarios is one of the main parts of the safety assessment methodology of nuclear power plants. Methods of disturbances scenario are also used in security researches [5].

For comparison, 110 different long term energy supply disturbance scenarios were developed. The basic scenario shows the current situation of the energy sector when primary energy supply disturbances do not exist until 2025, fuel and primary energy sources are supplied as it was predicted by demand for electric energy and heat production; also the change in prices of primary energy resources by average high forecasts of fuel prices [6]. The primary energy resources and fuel highly consumed in Lithuania are: oil products (boiler oil and orimulsion), gas, and nuclear fuel.

Scenarios of disturbances were modelled considering four parameters: part of the energy supply deviation of the basic supply scenario; the term of primary energy resources or fuel supply from the basic scenario; the price deviation of fuel or primary energy resources from the predicted price projected in the basic scenario; the moment (year) of supply deviation.

Probabilities were chosen considering the real Lithuanian situation: very high probabilities of deviations from basic scenarios were chosen for the gas supply (it can be supplied only by pipelines from Russia to Lithuania), smaller probabilities of deviations from the basic scenario were chosen for oil (it is possible to transport oil over the Butinge terminal from other countries).

\subsection{Modelling scenarios of energy disturbances and analysis of the results}

Energy disturbances were modelled using the Lithuanian energy system mathematical model developed in MESSAGE analytical software [4]. The assumption was taken that a new nuclear power plant could be built by 2018 . Its capacity would be $1600 \mathrm{MW}$. The model computes when NPP is necessary.

On every scenario quantity and price disturbances of the four main fuel types, which are used in Lithuania (gas, boiler oil, orimulsion and nuclear fuel), were 
modelled; this means the assumption that on a specified time the values differ from the specified starting value, which is obtained from the basic scenario case. Disturbance scenarios were developed modelling the upper limit of fuel consumption in the specific period. The limit can be smaller or larger than fuel consumption by a particular percentage in the basic scenario (starting quantity of fuel consumption). On another time of analysing period (where disturbances were not modelled) the fuel supply is not limited and the model can freely choose the optimal constitution of fuel balance.

Electric power can be produced in Lithuanian power plants or imported. Assumptions were made that $20 \%$ of the necessary electricity required can be imported. On the specific combinations of modelling disturbances (e.g., supply disturbance of two fuel types) a situation could occur when it is impossible to produce and to import the necessary amount of electricity. Such a case would result in unsupplied electricity to consumers. It is impossible to find a solution due to the particularity of the developed mathematical model of the energy system and calculations are stopped. Trying to avoid the above mentioned situation of unsupplied electricity results in a model requiring one more electricity importer, whose price is very high.

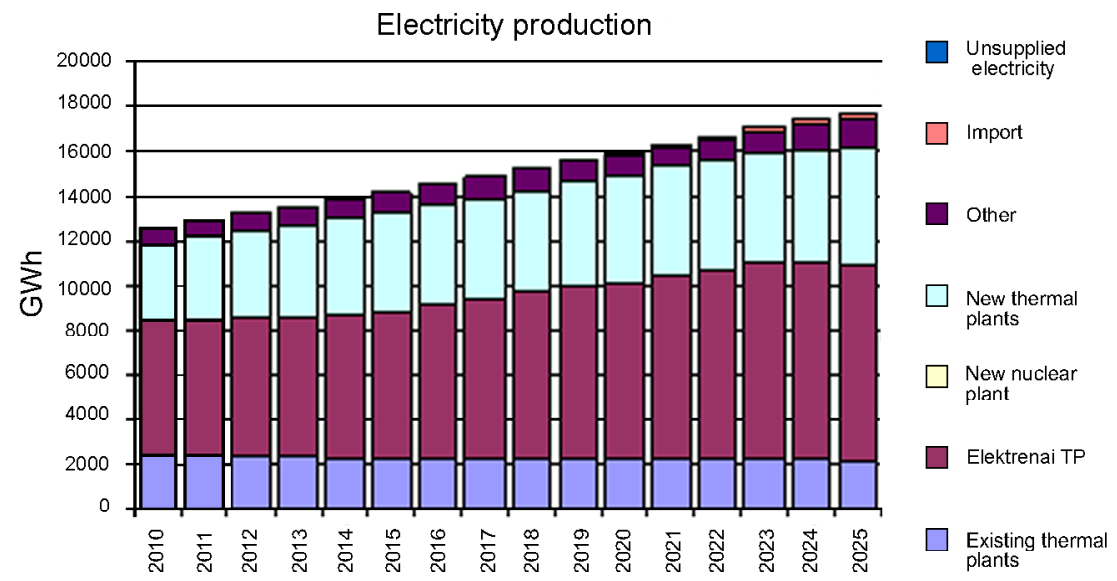

Figure 3: $\quad$ Electricity production - basic scenario.

In the case of basic scenarios, the production of electricity in the period of 2010-2025 is shown in Figure 3 and fuel consumption in energy production is shown in Figure 4. As we can see, the case of a Lithuanian Power Plant (PP) becoming the next main electricity producer after Ignalina NPP would produce $47-51 \%$ of all electricity energy. In the Lithuanian PP orimulsion would be used as the main fuel, which would compound $40-45 \%$ from all consumed fuel in the fuel balance for production of both electricity and heat in Lithuania. If, for different reasons, orimulsion couldn't be combusted in Elektrenai or its price was to rise substantially, combusted boiler oil or gas must be used in the plant. However, the production of electricity combusting gas in the current blocks of 
the Lithuanian PP wouldn't be effective and (sustaining the calculation results) it must build new combined cycle turbine blocks in Elektrenai or in others due to the higher efficiency of the blocks. A large part of electric energy (42-48\%) would be produced in the present or new thermal power plants (TPP). New NPP wouldn't be built on a basic scenario case.

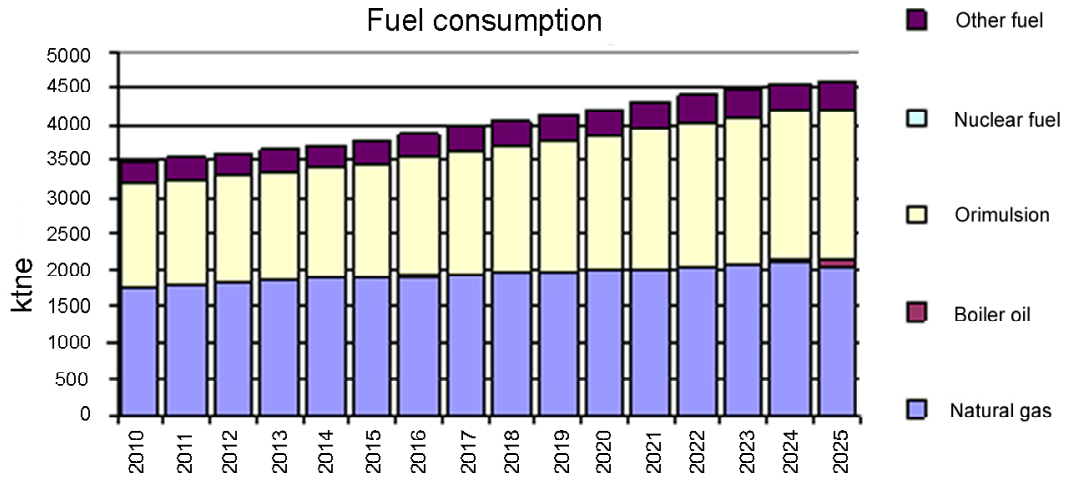

Figure 4: $\quad$ Fuel consumption - basic scenario.

In the case where the main fuel for electricity production is gas, which consists of $44-51 \%$ of all consumed fuel, the quantity of gas can be handled as minimal, because orimulsion (if it couldn't be consumed) would be changed by gas. Consumption of boiled oil is near zero.

All energy system costs per year were 15064615 thousand dollars (\$) per 15 years on the calculated case or 1004308 thousand dollars per year in a basic scenario.

Next to the basic scenario, 100 scenarios have been additionally modelled, which results in discounted energy system exploitation and development costs presented in Figure 5.

As can be seen from the results (Figure 5), the S90 scenario is an exceptional case among all main scenarios by the highest costs of total discounted energy system exploitations and development during the considered period. The scenario is specific because the supply of natural gas is broken to Lithuanian energy enterprises in 2014 for a year. The especially high costs comprise of both investment in mechanisms to reduce sulphur from smoke in the Lithuanian PP (in order to combust boiler oil instead of gas) and higher varying exploitation costs in the energy system.

The results of the calculations show that gas could be changed to boiler oil in the energy produce sector. It would raise consumption of other fuels (nuclear fuel, coal), but it would still remain as a very small part in general of the fuel balance. Electricity production in 2014 (when gas is unsupplied) in basic and S90 scenarios are shown in Figure 6. During other periods of time electricity producers of both scenarios are almost the same. It can be seen that the electricity quantity produced by the present TPP and the Lithuanian PP rises, 
because the power plants can change gas to boiler oil. Input of the new TPP causes the largest decrease. Part (10\% of all production) of electricity is imported. In summary it is possible to say that in the scenario the electricity demand is fully satisfied, but costs of its production rise (due to additional investments and consumption of high priced fuel).

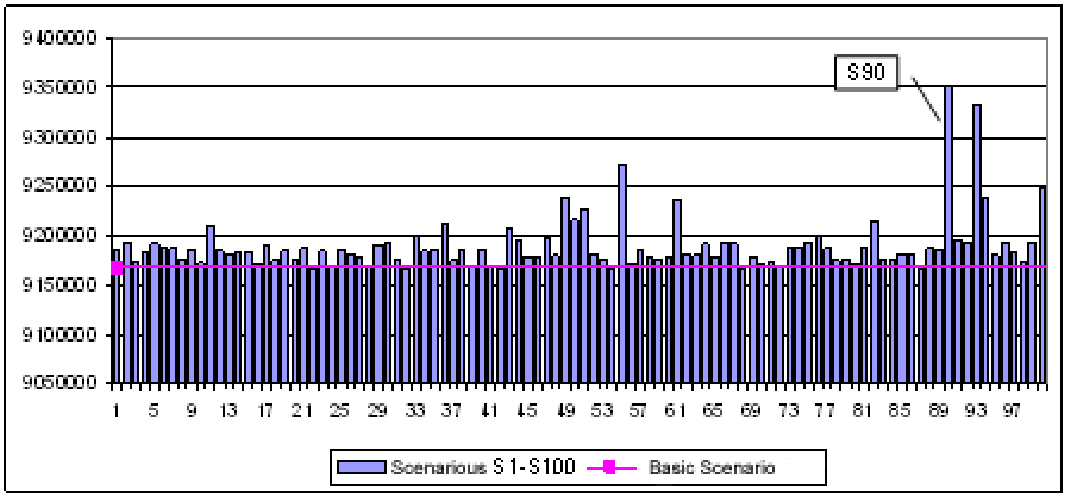

Figure 5: Discounted energy system exploitation and development costs, in thousands of dollars.

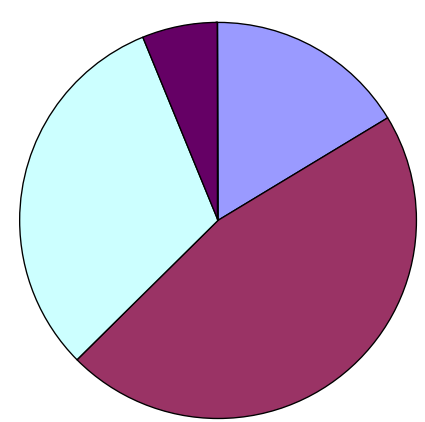

a) basic scenario

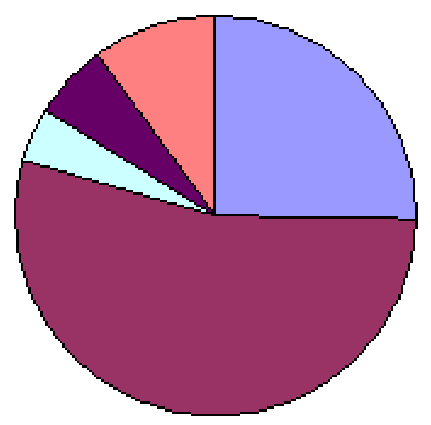

b) S90 scenario.

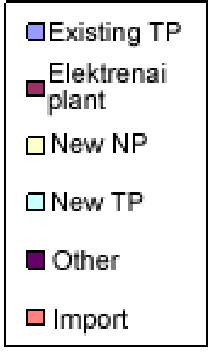

Figure 6: $\quad$ Electricity production in $2014 \mathrm{~m}$. on basic and S90 scenarios.

\section{Results and conclusions}

\subsection{Results}

1) Energy supply security problems and the Lithuanian situation are shown in the paper.

2) The methodology of energy supply assessment is presented. 
3) The mathematical model of energy disturbances is created in the paper. It is chosen and modelled in 110 different scenarios of energy disturbances.

\subsection{Conclusions}

1) Low level disturbances of electric energy (reducing to $50 \%$ from basic scenarios) of different fuel types (gas, oil, boiler oil, orimulsion, nuclear fuel) do not cause substantial harm to the Lithuanian energy system.

2) When the gas supply decreases to $95 \%$ for a year, the gas supply is stopped to Lithuanian enterprises but electricity and heat is then produced by boiler oil. Therefore, the cost of energy production rises by $\$ 51$ million per year on average.

3) A critical situation is reached when the supply of two fuel types to Lithuania is stopped.

\section{References}

[1] Revised and renewed national program of energy consumption and efficiency increasing. Confirmed by order of LR economy ministre No. 319, October 26, 2001.

[2] National energy strategy. Certified by resolution of LR parlament No. X1046, January 18, 2007, http://www3.lrs.lt/pls/inter3/dokpaieska.showdoc $1 ? \mathrm{p} \_\mathrm{id}=291371$.

[3] Energy in Lithuania 2001, 2002, 2003, 2004, 2005, 2006. Compiled by Juska and Miskinis. Lithuanian energy institute.

[4] Norvaisa E. Modelling and Analysis of Sustainable Development of Lithuanian Power and Heat Supply Sectors, Doctoral thesis, Kaunas 2004.

[5] Tani S. N. Decision Analysis of the Synthetic fuels Commercialization Program, Proc. of the National Computer Conference, 1978, AFIPS Vol. 47, pp. 23-29.

[6] Analysis of energy sector development trends and predictions till 2025. 2006. Lithuanian energy institute. 